$\lambda \circ \gamma \circ \varsigma$

Studien zur Logik, Sprachphilosophie und Metaphysik

Herausgegeben von / Edited by

Volker Halbach • Alexander Hieke

Hannes Leitgeb • Holger Sturm

Band 4 / Volume 4 
Hans Rott / Vítezslav Horák (Eds.)

\title{
Possibility and Reality
}

\author{
Metaphysics and Logic
}

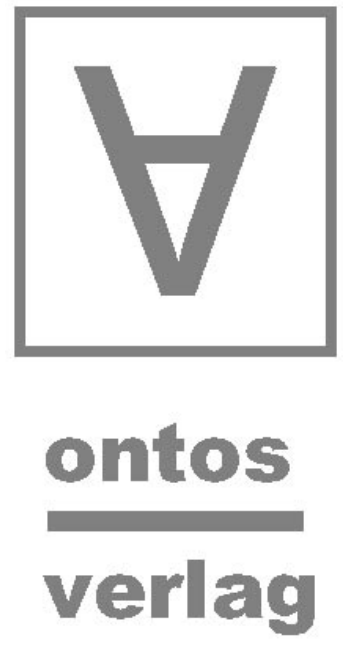

Frankfurt - London 


\title{
Bibliographic information published by Die Deutsche Bibliothek
}

Die Deutsche Bibliothek lists this publication in the Deutsche Nationalbibliographie; detailed bibliographic data is available in the Internet at http://dnb.ddb.de

\author{
${ }^{\circ} 2003$ ontos verlag \\ Postfach 6105 16, D-60347 Frankfurt a.M. \\ Tel. ++(49) 6940894151 Fax ++(49) 6940894169 \\ www.ontos-verlag.de \\ ISBN 3-937202-24-2 (Germany)
ISBN 1-904632-13-0 (U.K.; U.S.A.)
}

Alle Texte, etwaige Grafiken, Layouts und alle sonstigen schöpferischen Teile dieses Buches sind u.a. urheberrechtlich geschützt. Nachdruck, Speicherung, Sendung und Vervielfältigung in jeder Form, insbesondere Kopieren, Digitalisieren, Smoothing, Komprimierung, Konvertierung in andere Formate, Farbverfremdung sowie Bearbeitung und Übertragung des Werkes oder von Teilen desselben in andere Medien und Speicher sind ohne vorherige schriftliche Zustimmung des Verlages unzulässig und werden verfolgt.

Gedruckt auf säurefreiem, alterungsbeständigem Papier, hergestellt aus chlorfrei gebleichtem Zellstoff (TcF-Norm).

Printed in Germany. 